\title{
CONTROLE FUZZY DE ROBÔ DIFERENCIAL
}

\author{
J. P. Reges, J. L. N. Silva, L. C. S. Bezerra, A. R. Alexandria \\ Instituto Federal do Ceará \\ jonas_platini@hotmail.com \\ Submetido 26/05/2015 - Aceito 20/11/2017 \\ DOI: $10.15628 /$ holos.2017.3089
}

\section{RESUMO}

O presente trabalho descreve de forma sucinta o projeto de desenvolvimento de um robô móvel com acionamento diferencial com inteligência artificial. A inteligência artificial empregada é baseada na técnica conhecida como lógica fuzzy. A inteligência embarcada tem dois objetivos principais atingir o alvo e evitar colisões na execução da trajetória. É apresentada uma metodologia para desenvolver um controlador fuzzy no Matlab ${ }^{\circledR}$ que realiza estas funções. Também são apresentadas as tecnologias utilizadas no robô móvel sensores de distância, comunicação Bluetooth e materiais reutilizados na montagem do robô. $O$ ambiente ou cenário de simulação é um corredor estreito e o robô se move baseado somente nos sinais enviados pelos sensores de distância embarcados. No final são realizadas simulações e apresentados os resultados do robô móvel navegando em um ambiente desconhecido.

PALAVRAS-CHAVE: Robô móvel, Acionamento diferencial, Inteligência Artificial, Lógica fuzzy.

\section{FUZZY CONTROL DIFFERENTIAL ROBOT}

\section{ABSTRACT}

This paper briefly describes the development of a mobile robot with differential drive using artificial intelligence. Artificial intelligence is employed based on the technique known as fuzzy logic. The embedded intelligence has two main objectives to reach the target and avoid collisions in executing the path. A methodology is presented to develop a fuzzy controller in Matlab ${ }^{\circledR}$ that performs these functions. Technologies used in mobile robot are presented such as distance sensors, Bluetooth communication and materials reused in robot assembling. The simulation environment scenario is a narrow corridor and the robot moves based only on signals sent by embedded sensors. At the end simulations are carried out and the results of the mobile robot navigating in an unknown environment are presented.

KEYWORDS: Mobile Robot, Differential Drive, Artificial Intelligence, Fuzzy. 


\section{INTRODUÇÃO}

O precursor do termo robô foi Karel Capek, novelista e escritor de uma peça teatral da Tchecoslováquia, que usou pela primeira vez, em 1920, a palavra "robota" (serviço compulsório, atividade forçada) originando a palavra "robot" em inglês e traduzido para o português como "robô" (Groover, Weiss, \& Nagel, 1986). Diversos filmes de ficção científica mostraram os robôs produzidos com o comportamento e a forma humana, levando muitos entusiastas e pesquisadores a desenvolverem robôs para o mundo real. Com o surgimento dos computadores na metade do século passado, iniciaram-se especulações em termos da capacidade de um robô pensar e agir como um ser humano, a Inteligência Artificial (Niku, 2014). No entanto, os robôs foram, neste período, desenvolvidos especialmente para executarem tarefas difíceis, perigosas e enfadonhas para um ser humano (Carrara, 2007).

A Robótica móvel é a área da robótica que estuda os mecanismos que podem se locomover pelo seu ambiente, não estando restritos a uma base fixa. Uma das principais categorias de robôs móveis são os robôs terrestres, que se movimentam no solo da terra e de outros planetas utilizando dispositivos como rodas, esteiras e pernas (Siegwart, 2004). Neste trabalho será utilizado um robô móvel terrestre com rodas conhecido como robô diferencial (Delgado-Mata, 2012). Um robô de tração diferencial é provavelmente o robô terrestre de mais fácil construção. Ele é constituído de duas rodas montadas em um eixo imaginário e tracionadas por motores elétricos independentes.

A navegação é a capacidade que o robô necessita para percorrer o ambiente sem colidir com os obstáculos, determinar a própria posição, e atingir determinados locais através de metas. Contudo, o sistema de navegação pode implicar os seguintes componentes: sistema de posicionamento do robô, planejamento de trajetória e mapa de construção (Zaki, 2014). O controle dos motores geralmente é feito por um controlador clássico, baseado somente em um modelo matemático. Utilizando esta técnica os robôs ficam limitados a trabalhar numa de faixa operação chamada linear e em ambientes conhecidos (Resende, 2013). Neste trabalho tem-se o objetivo de utilizar inteligência artificial como controlador e fazer com isso o robô diferencial seguir uma trajetória desejada em um ambiente desconhecido livre de colisão.

A lógica fuzzy é uma técnica de inteligência artificial baseada na teoria dos conjuntos fuzzy (nebulosos) (Niku, 2014). Tradicionalmente, uma proposição lógica tem dois extremos: ou é "completamente verdadeiro" ou é "completamente falso". Entretanto, na lógica fuzzy, uma proposição lógica varia em grau de verdade de 0 a 1 . O que leva a ser o valor de uma variável parcialmente verdadeiro ou parcialmente falso, descrito por funções contínuas denominadas funções de pertinência (Simões, 2007). No trabalho (Pradhan, Parhi, \& Panda, 2009) é realizado um comparativo utilizando diferentes funções de pertinência para a navegação de robôs móveis, retratando que os robôs são capazes de evitar a colisão com obstáculos e atingir metas com eficiência.

O controle executado pela lógica fuzzy tenta reproduzir o comportamento de um operador humano que trabalha baseado em regras ao invés de um controlador clássico que trabalha restrito a modelos matemáticos, como em equações diferenciais e modelos no domínio da frequência (Niku, 2014). O objetivo da lógica fuzzy é gerar uma saída lógica a partir de um conjunto de entradas imprecisas, vagas, com ruídos ou até mesmo faltantes. A lógica fuzzy tem 
por essência gerar valores de saídas (sinais de controle) sem a necessidade de entradas precisas nem modelos matemáticos complexos (Pandey \& Parhi, 2014).

Neste trabalho a simulação faz o robô planejar e seguir uma trajetória em ambiente desconhecido, onde se encontram dois obstáculos, que formam um corredor estreito. O robô deve atravessar este corredor para atingir o alvo sem colidir com os obstáculos (Pandey \& Parhi, 2014). Este cenário foi escolhido pelo seguinte fato: para o robô que tem como sinais de entrada apenas sensores de distância, um corredor estreito é equivalente a duas retas paralelas. Se fosse um robô baseado puramente na matemática ele poderia chegar a seguinte conclusão "duas retas paralelas se cruzam no infinito, então é melhor eu parar antes que a distância entre as retas se torne nula e eu fique preso". No entanto, a inteligência artificial baseada em lógica fuzzy permitirá que robô se comporte como um operador humano e tentará atingir alvo sem colidir com os obstáculos, qualquer outra decisão do controlador surgirá da fusão das regras criadas no momento do projeto do controlador fuzzy.

\section{REVISÃO BIBLIOGRÁFICA}

\subsection{Robótica móvel}

Os robôs móveis possuem uma larga escala de utilização, podendo ser autônomos, semiautônomos e comandados por telemetria. Nos robôs autônomos existem diversas tecnologias de percepção do ambiente, controle da velocidade de movimentação, distância percorrida, entre outras medições. A robótica tem uma serie de aplicações na indústria, educação, lazer e nas pesquisas (Guimarães, 2006). Em (Niku, 2014) é mostrado que um robô sozinho é inútil, este deve vir acompanhado com acessórios que podem ser dispositivos periféricos, sensores, garras, câmeras, entre outros.

Alguns robôs autônomos aplicados à navegação são dotados de técnicas que selecionam diferentes esquemas estratégicos para se alcançar o mesmo objetivo, alguns esquemas são formados usando conhecimentos prévios do ambiente, denominado arquitetura de controle deliberativa. Entretanto, alguns esquemas estratégicos são formados usando dados sensoriais atuais do robô em navegação criando assim um caminho seguro, denominada arquitetura de controle reativa (Romero, Preste, Osório, \& Wolf, 2014). Este comportamento estratégico pode ser alcançado através de uma arquitetura reativa baseada em lógica fuzzy (Huq, Mann, \& Gosine, 2008). Em RESENDE (2013), é proposto um controlador de rastreamento de trajetórias não lineares para robôs móveis com controlador baseado em lógica fuzzy, onde as regras fuzzy foram projetadas com o objetivo de limitar os sinais de controle, bem como reduzir os erros decorrentes da dinâmica do robô.

Em (Jaradat, Al-Rousan, \& Quadan, 2011) é mostrado que na navegação de robôs móveis em ambientes desconhecidos existem os seguintes problemas: a localização do próprio robô e a geração do caminho planejado (desejado). Onde a localização é o processo de determinação da posição e orientação do robô em relação aos sistemas coordenadas global e local. Desta forma o robô tem de reconhecer os objetos ao seu redor. Podendo reconhecer cada objeto como um alvo ou como um obstáculo para gerar o caminho livre de colisão (Romero, Preste, Osório, \& Wolf, 2014). Muitas técnicas implementadas para a resolução destes problemas utilizam a localização 
por meio de sensores a laser, sensores ultrassônicos, sensores infravermelho, sensores de visão e GPS que podem ser desenvolvidas on-board ou off-board. Quando a exibição do ambiente é necessária, uma rede de câmeras pode ser utilizada (Abiyev, Ibrahim, \& Erin, 2010).

\subsection{Lógica fuzzy}

Esta técnica de inteligência artificial foi introduzida nos meios científicos em 1965 por Lofti Asker Zadeh, através da publicação do artigo fuzzy Sets no Jornal Information and Control. Atualmente é um elemento fundamental em diversos sistemas, sendo considerada uma das técnicas com melhores resultados no universo computacional (Chenci, Rignel, \& Lucas, 2011). Outras técnicas de inteligência artificial como as Redes Neurais Artificiais podem ser fundidas com a lógica fuzzy, dando origens aos sistemas híbridos denominados neuro-fuzzy (Lopes, Santos, \& Pinheiro, 2014). Em (Demirli \& Khosnejad, 2009) são apresentados trabalhos baseados na lógica neuro-fuzzy, onde foi desenvolvido um robô móvel que faz o estacionamento paralelo e de forma autônoma em locais de dimensões desconhecidas, utilizando três sensores ultrassônicos para decidir o ângulo de giro do robô na hora do estacionamento. Em (Zaki, 2014) é projetado um robô inteligente para navegação autônoma que utiliza vinte e quatro sensores ultrassônicos interligados ao um sistema microcontrolado na detecção de obstáculos.

Durante a construção de um robô móvel é ideal a realização de simulações para treinamentos e testes, obtendo-se assim resultados, onde a partir deste possam ser realizadas melhorias no projeto. Estas simulações podem ser realizadas em ambiente computacionais para a navegação do robô móvel, em (Pandey \& Parhi, 2014) esta simulação foi realizada no $M A T L A B \mathbb{R}$ e usando uma lógica de controle fuzzy, foi possível simular a navegação mesmo com a inserção de obstáculos desordenados. Em (Moustris \& Tzafestas, 2011), é proposto um controlador baseado em lógica fuzzy para robôs móveis que apresentam uma restrição de curvatura limitada, monitorando e fazendo uma aproximação do caminho de referência possível, para o monitoramento de linhas retas.

\subsection{Sensores}

Os sistemas robóticos autônomos são dotados de vários sensores que são empregados, normalmente, em combinação com outros sensores. Podendo ser complementares ou redundantes, dependendo da aplicação. Logo, na maioria dos sistemas robóticos são usados sensores múltiplos do mesmo tipo ou de tipos diferentes para proporcionar uma maior cobertura do ambiente (Romero, Preste, Osório, \& Wolf, 2014) (Zaki, 2014). Em (Giannoccaro \& Spedicato, 2013) foram utilizados quatro sensores ultrassônicos que faziam a exploração do espaço circundante, detectando as paredes do ambiente e outros objetos estáticos visando proporcionar ao robô consciência do seu meio inserido. Em (Pereira, Galdino, \& Almeida, 2009) foi desenvolvido um robô para ser utilizado na inspeção de áreas com difícil acesso contendo um módulo de rádio para a comunicação entre o robô e o computador e um sistema de captação e transmissão de imagens sem fio.

Os sensores ultrassônicos funcionam com um emissor e um receptor, calculando há distância do objeto em relação sensor pela reflexão da onda, estes sensores sofrem de respostas não confiáveis do ambiente, como a faixa do sonar que tem formato de cone e o objeto pode 
estar localizado em qualquer local da área, não havendo uma maneira exata da posição do objeto ou pode sofrer pelo efeito da reflexão especular (Kumari, 2012) (Giannoccaro \& Spedicato, 2013) (Romero, Preste, Osório, \& Wolf, 2014).

\section{METODOLOGIA}

\subsection{Materiais utilizados}

A estrutura física do robô móvel foi construída com materiais de baixo custo. Basicamente foram utilizados pedaços de madeira, dois motores de corrente contínua (CC) de 5 Volts e rodas de plásticos com caixas de redução acopladas, utilizadas para brinquedos. Para controlar o acionamento dos motores CC e gerenciar a comunicação com o controlador fuzzy foi embarcado no robô um Microcontrolador Arduino UNO. O Microcontrolador é responsável pela leitura dos sinais elétricos enviados pelos sensores de distância e a conversão destes em distâncias medidas em centímetros (Zaki, 2014).

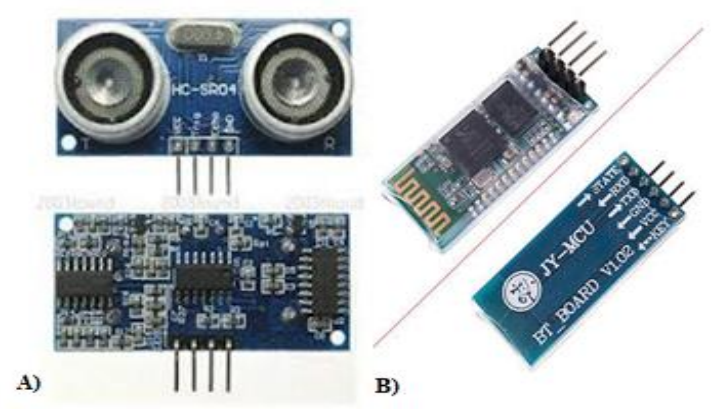

Figura 1 - A) Sensor ultrassônico de distância embarcado no robô. Fonte:

http://automatobr.blogspot.com.br/2013_07_01_archive.html. B) Bluetooth embarcado no robô móvel. Fonte: http://www.ebay.com/itm/5V-JY-MCU-HC-06-V1-04-Bluetooth-Transeiver-RF-Module-Serial-Port-51-AVR-MCUARM-/261121350024.

Os sensores ultrassônicos foram embarcados no robô e sua função é medir a distância do robô aos obstáculos, no projeto foi utilizado o sensor ultrassônico HC-SR04. Na figura 1A é possível ver o emissor e receptor do sensor ultrassônico. Estes sensores estão entre os mais frequentemente usados em robótica móvel. De fato, diversos trabalhos têm empregado tais sensores (Demirli \& Khosnejad, 2009), em tarefas como construção de mapas do ambiente de trabalho, detecção de obstáculos, navegação, reconhecimento de padrões. O funcionamento do mesmo é baseado na medição do tempo de voo de uma onda mecânica ( $20 \mathrm{KHz}$ ) emitida pelo cristal do sensor e refletida no obstáculo.

A Comunicação sem fio entre o robô móvel e o computador mestre é realizada através do protocolo de comunicação Bluetooth. Bluetooth é uma tecnologia de transmissão sem fio para pequenas distancias. Suas principais características são: baixo consumo de energia, robustez e baixo custo, no projeto foi utilizado o módulo Bluetooth Serial RS232. É um padrão largamente utilizado ao longo do mundo principalmente para interligar pequenos dispositivos como os celulares, notebooks e periféricos de computador. Estes dispositivos formam entre si uma rede chamada de "piconets" que se estabelece automaticamente e dinamicamente assim que os dispositivos habilitados entram em seus raios de proximidade (Silva, 2012). Na figura 1B é mostrado o equipamento Bluetooth embarcado no robô. 
Na Figura 2 é mostrado o robô diferencial desenvolvido neste trabalho. Na figura é possível identificar os três sensores ultrassônicos, instalados na posição frontal, posição direita e posição esquerda para detectar obstáculos. Também são mostrado o módulo Bluetooth e as rodas de plástico.

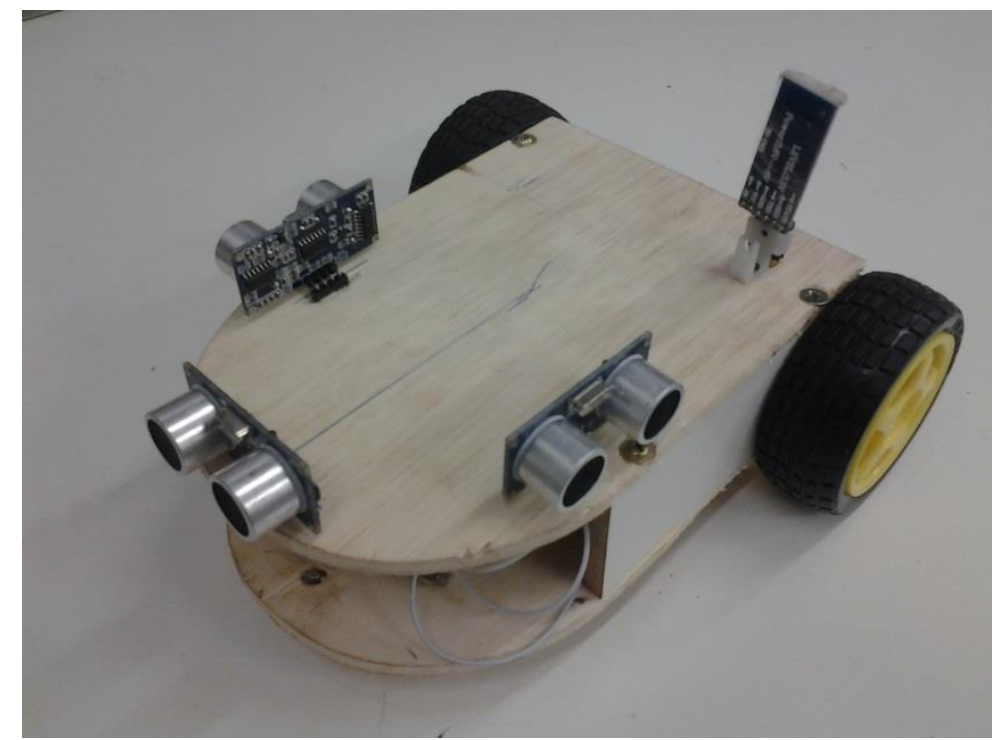

Figura 2 - Robô móvel desenvolvido. Fonte: os autores.

O programa Matlab ${ }^{\circledR}$ é uma ferramenta poderosa utilizada em computação numérica em diversas áreas científicas e tem se tornando um ambiente efetivamente foi utilizado neste trabalho para realizar cálculos matemáticos, desenvolver algoritmos, modelagem e simulação do robô móvel navegando em um ambiente com obstáculos. A principal vantagem do uso deste programa é a existência de várias bibliotecas chamadas de toolboxes.

Uma biblioteca muito importante que está disponível no Matlab ${ }^{\circledR}$ é o Fuzzy Logic Toolbox que contém uma interfase gráfica que permite a construção de sistemas fuzzy e efetiva implementação em tempo real. Esta ferramenta foi adotada neste trabalho para o desenvolvimento e simulação do controlador fuzzy (Nascimento Junior, 2004) (Simões, 2007). A tela básica é chamada de FIS (fuzzy Inference System) está representa na Figura 3 e é nela que o controlador fuzzy é desenvolvido. Os passos adotados neste trabalho para desenvolver o controlador fuzzy são:

1. Escolha das variáveis de entrada e saída; variáveis de entrada adotadas foram o erro de posição instantâneo e a distância do robô até os obstáculos, as variáveis de saídas adotadas foram às velocidades das duas rodas definidas pela tensão elétrica nos motores das rodas. A Figura 3 mostra essas definições. 


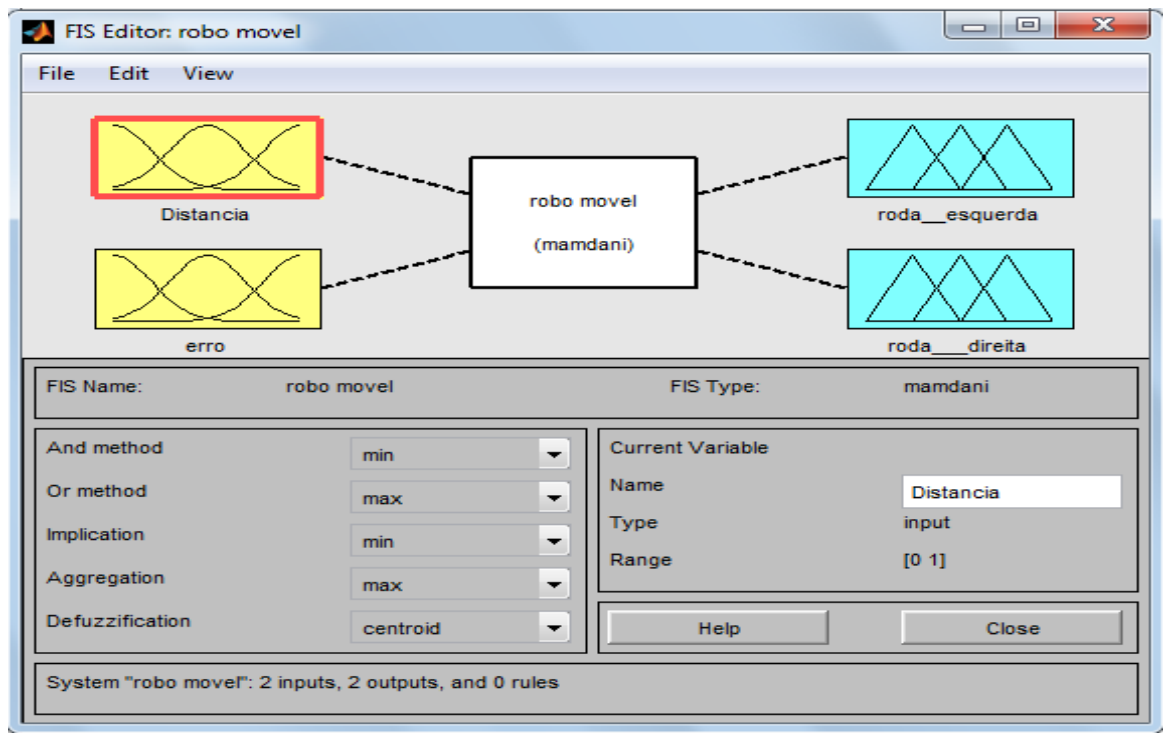

Figura 3 - Tela de edição do FIS - Fuzzy Inference System. Fonte: os autores.

2. Definição dos universos de discurso para as variáveis de entrada e de saída; os universo de discursos adotados foram variações que respeitam os limites fisicos dos sensores e atuadores embarcados. Portanto a entrada Distância até obstáculo varia de $-25 \mathrm{~cm}$ a $25 \mathrm{~cm}$, o erro de posição varia $-20 \mathrm{~cm}$ a $20 \mathrm{~cm}$, as velocidades das rodas variam de $-5 \mathrm{~V}$ a $5 \mathrm{~V}$.

3. Definições das funções de pertinência para os termos linguisticos das variáveis consideradas ("fuzificação" das entradas e saídas); foram adotadas três funções traingulares simétricas com 50\% de sobreposição para cada variável (Niku, 2014). A Figura 4 mostra essas funções para a variável de entrada Erro de posição. As funções triangulares foram implementadas no controladores como a intersecção de funções lineares.

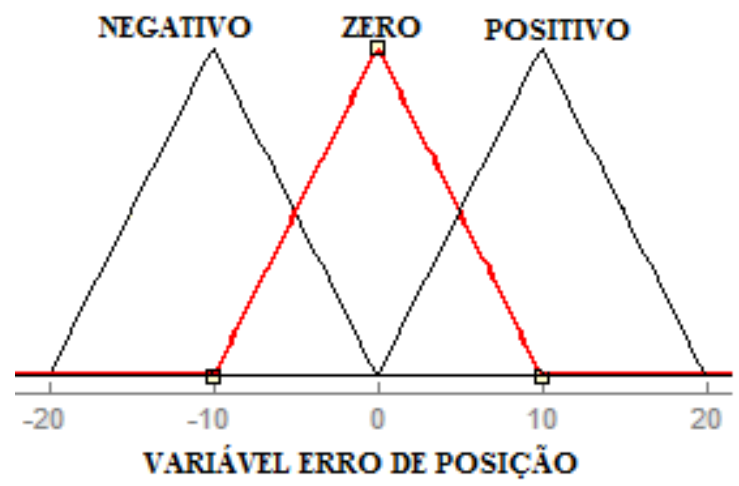

Figura 4 - Funções de Pertinência Triangulares adotadas. Fontes: os Autores.

4. Construção das regras de inferência a utilizar; as regras são baseadas na relação se (variável entrada) então (variavel de saída). Também são seguidas as relações fisicas entre as variáveis de acordo com as equações do modelo matemático do robô diferencial com o objetivo de levar o erro de posição a zero e manter uma distância segura dos obstáculos. Foram criadas umtotal de nove regras.

5. "desfuzificação" das saídas. Esta etapa consiste em converter a variável linguísta num valor númerico. $\mathrm{O}$ método adotado neste trabalho é conhecido como defuzificação Mamdani ou 
centróide que consiste em determinar o centro geométrico da área definida pela função de pertinência das variáveis (Nascimento Junior, 2004) (Simões, 2007).

\subsection{Modelagem matemática}

Por definição, para se controlar um robô móvel no plano cartesiano é necessário e suficiente controlar sua posição em relação aos eixos $X$ e $Y$ e mais o ângulo de orientação. Conforme mostrado na Figura 2 para o robô diferencial usado neste trabalho. Desta forma, temse um sistema MIMO (Multiple Input, Multiple Out) representado pela equação 1 , contendo duas entradas e três saídas (AGUIRRE, 2010):

$(X(t), Y(t), \theta(t))=F\left(V_{r}(t), V_{l}(t)\right)$

onde $X(t), Y(t)$ : posição do robô em relação aos eixos $X$ e $Y ; \theta(t)$ : orientação do robô (ângulo com o eixo $X) ; V_{1}(t)$ : tensão elétrica aplicada ao motor esquerdo [volts]; $V_{r}(t)$ : tensão elétrica aplicada ao motor direito [volts].

Para o robô andar em linha reta é necessário imprimir velocidades iguais em módulo e de mesmo sentido para ambos os motores. Para que o robô gire sobre o seu eixo são colocadas velocidades iguais e de sentidos opostos. Para a realização de curvas são usadas combinações desses casos, ou seja, para realizar movimentos circulares são necessários velocidades de módulos diferentes nas rodas (Delgado-Mata, 2012). Com o intuito de adicionar a informação sobre a dinâmica do robô faz-se necessária a construção de um modelo matemático mais detalhado. Para isso, parte-se das equações que descrevem o comportamento dos motores que impulsionam o robô. A função de transferência (Huq, Mann, \& Gosine, 2008) do motor DC pode ser aproximada por um sistema de primeira ordem como sendo:

$q(s)=\frac{K}{T s+1} V(s)$

onde K: ganho do motor [radiano/(volts*segundo)]; T: constante de tempo do sistema [segundo]; $\mathrm{V}(\mathrm{s})$ : tensão elétrica aplicada ao motor [volts]; q(s): velocidade angular do eixo do motor [rad/s]. Escrevendo a equação (2) na forma de equações diferenciais no domínio do tempo para cada um dos motores temos:

$$
\begin{aligned}
& \dot{q}_{l}(t)=-\frac{1}{T_{l}} q_{l}(t)+\frac{K_{l}}{T_{l}} V_{l}(t) \\
& \dot{q}_{r}(t)=-\frac{1}{T_{r}} q_{r}(t)+\frac{K_{r}}{T_{r}} V_{r}(t)
\end{aligned}
$$

onde $\mathrm{T}_{\mathrm{r}}$ : constante de tempo do motor direito [segundo]; $\mathrm{T}_{1}$ : constante de tempo do motor esquerdo [segundo]; $V_{I}(t)$ : tensão elétrica aplicada ao motor esquerdo [volts]; $V_{r}(t)$ : tensão elétrica aplicada ao motor direto [volts]; $\mathrm{K}_{\mathrm{r}}$ : ganho do motor direito [radianos/(volts.segundos)]; $\mathrm{K}_{\mathrm{l}}$ : ganho do motor esquerdo [radianos/(volts.segundos)].

Assim, um modelo matemático que inclui tanto a cinemática quanto a dinâmica de primeira ordem dos motores de um robô móvel pode ser equacionada como: 


$$
\begin{aligned}
& \dot{x}(t)=\frac{r}{2} \cos (\theta(t)) q_{r}(t)+\frac{r}{2} \cos (\theta(t)) q_{l}(t) \\
& \dot{y}(t)=\frac{r}{2} \operatorname{sen}(\theta(t)) q_{r}(t)+\frac{r}{2} \operatorname{sen}(\theta(t)) q_{l}(t) \\
& \dot{\theta}(t)=-\frac{r}{2 R} q_{r}(t)+\frac{r}{2 R} q_{l}(t)
\end{aligned}
$$

onde $q_{1}(t)$ : velocidade angular do eixo do motor esquerdo [rad/s]; $q_{r}(t)$ : velocidade angular do eixo do motor direito [rad/s]; R: metade da distância entre as rodas ou raio do carro [metros]; r: metade do diâmetro das rodas ou raio das rodas [metros]. Um controlador clássico faria o robô móvel realizar a geração de trajetória segundo as equações (5), (6) e (7) (Aguirre, 2007) (Dudek \& Jenkin, 2010) (Siegwart, 2004). Neste trabalho essas equações são úteis para ajustar os limites das variáveis de entrada e saída do controlador fuzzy e também para permitir a simulação no ambiente virtual criado no Matlabß

\section{RESULTADOS E DISCUSSÕES}

Consideremos o cenário da simulação em que o robô deve atravessar um corredor estreito para alcançar um alvo. $O$ experimento consiste em fazer o robô diferencial navegar em um corredor estreito sem colidir com as paredes. O ambiente de criado para simulação (Figura 5) consiste num quadrado com $420 \mathrm{~cm}$ de lado, onde se encontram dois obstáculos, que formam um corredor estreito ( $80 \mathrm{~cm}$ de largura). O robô deve atravessar este corredor para atingir o alvo. Utilizando a técnica de inteligência artificial baseada em lógica fuzzy, pode-se observar que o robô realiza a trajetória sem ocorrer à existência de mínimos locais (pontos onde controlador para de enviar sinais de controle, tensão para rodas, achando que atingiu o alvo sem ter atingindo) que é um problema em vários controladores clássicos.

Utilizando como referência para o controlador fuzzy uma velocidade constante, foi obtida a trajetória apresentada na Figura 6. Na mesma figura, à direita, podemos observar a evolução temporal do robô. Assim, o robô segue em frente ao longo do corredor em direção do alvo não apresentando um comportamento muito agitado, ou seja, não apresentando variações na sua direção oscilando entre movimentos à direita ou à esquerda dentro do corredor. Assim, o robô segue em frente, ao longo do corredor, pois a distância entre os dois obstáculos permite a sua passagem. 


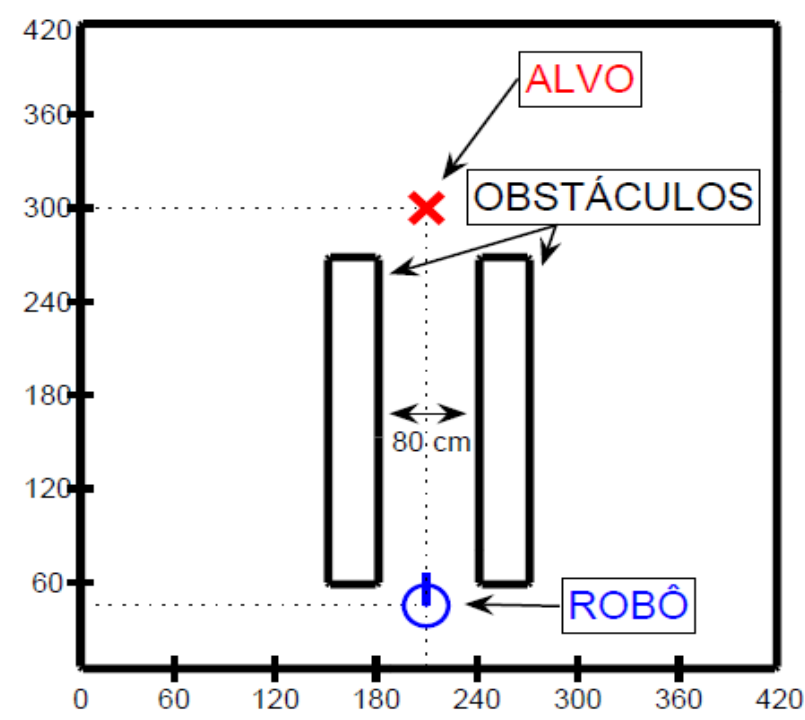

Figura 4 - Ambiente de simulação: Passagem do robô por um corredor estreito. Fonte: os autores.

\section{CONCLUSÃO}

A lógica fuzzy representa uma forma inovadora de manuseio de informações imprecisas, como a leitura dos sensores ultrassônicos, fornecendo um método de traduzir expressões verbais, vagas, imprecisas e qualitativas, comuns na comunicação humana, em valores numéricos. Durante a execução deste trabalho observa-se que a tecnologia fuzzy tem um imenso valor prático, na qual se torna possível a inclusão da experiência de operadores humanos.

Baseado nos resultados das simulações computacionais e experimentais pode-se afirmar que, para a automação e o controle de sistemas robóticos, a aplicação de técnicas inteligentes como a lógica fuzzy pode ser de alto retorno na solução de problemas de seguimento de trajetória e desvio de obstáculos, seja pelo aumento de eficiência nos controladores, seja pela implementação automatizada de estratégias de controle anteriormente delegadas apenas a operadores humanos. Outro ponto importante é que o modelo matemático do robô não precisa ser preciso, apenas aproximações para desenvolver as variáveis do controlador são suficientes para um excelente desempenho.

Para trabalhos futuros poderão ser implementados ambientes de navegação com nível de complexidade maior, como curvas e desvios de obstáculos em repouso e/ou movimento. Aprimorando assim, a técnica do acionamento diferencial baseado na lógica fuzzy utilizada no trabalho apresentado. 


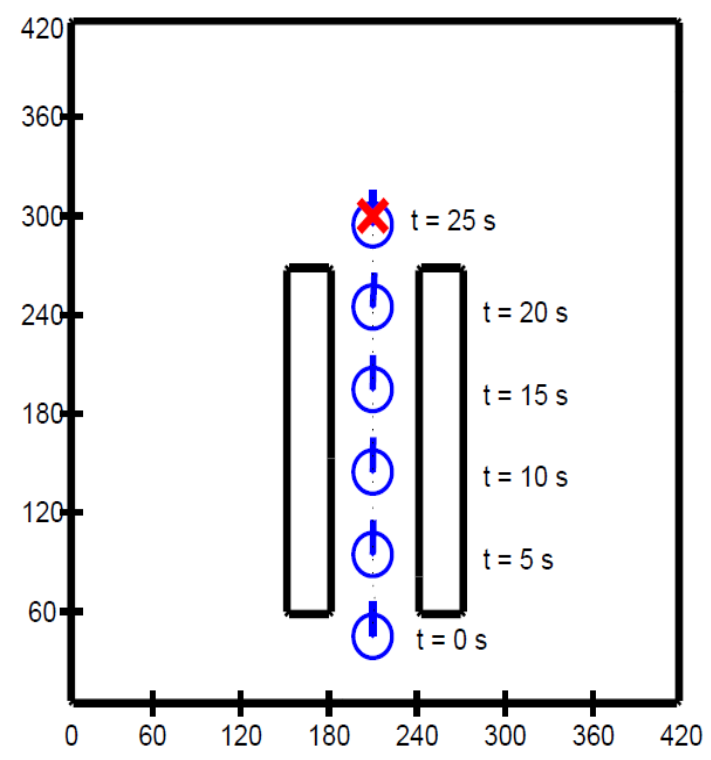

Figura 5 - Execução da simulação. Fonte: os autores.

\section{BIBLIOGRAFIA}

Abiyev, R., Ibrahim, D., \& Erin, B. (Outubro de 2010). Navigation of mobile robots in the presence of obstacles. Advances in Engineering Software, 41(10), 1179-1186.

Aguirre, L. A. (2007). Enciclopédia de Automática: Controle e Automação (Vol. 3). São Paulo: Blucher.

Carrara, V. (2007). Robótica. Universidade Braz Cubas: Apostila dos cursos de engenharia mecânica e engenharia de controle e automação.

Chenci, G. P., Rignel, D. G., \& Lucas, C. A. (2011). Uma introdução á lógica Fuzzy. Revista Eletrônica de Sistemas de Informação e de Gestão Tecnológica, 1(1), 17-28.

Delgado-Mata, C. (2012). A Differential-Drive Mobile Robot Driven by an Ethology Inspired Behaviour Architecture. Procedia Technology, 3, 157-166.

Demirli, K., \& Khosnejad, M. (2009). Autonomous parallel parking of a car-like mobile robot by a neuro-fuzzy sensor-based controller. Fuzzy Sets and Systems, 160(19), 2876-2891.

Dudek, G., \& Jenkin, M. (2010). Computational principles of mobile robotics. Cambridge: Cambridge university press.

Giannoccaro, N. I., \& Spedicato, L. (2013). Exploratory data analysis for robot perception of room environments by means of an in-air sonar scanner. Ultrasonics, 53(6), 1163-1173.

Groover, M. P., Weiss, M., \& Nagel, M. N. (1986). Industrial robotics: technology, programming and application. McGraw-Hill Higher Education.

Guimarães, F. d. (2006). Desenvolvimento de robô móvel utilizado para a exploração de ambientes hostis. Mauá: Dissertação de Mestrado em Engenharia de Processos Químicos e Bioquímicos, Instituto Mauá de Tecnologia.

Huq, R., Mann, G. K., \& Gosine, R. G. (2008). Mobile robot navigation using motor schema and fuzzy context dependent behavior modulation. Applied soft computing, 8(1), 422-236.

Jaradat, M. A., Al-Rousan, M., \& Quadan, L. (2011). Reinforcement based mobile robot navigation in dynamic. Robotics and Computer-Integrated Manufacturing, 27(1), 135-149.

Kumari, C. L. (2012). Building algorithm for obstacle detection and avoidance system for wheeled mobile robot. Global Journal of Research In Engineering, 12(11), 1-5. 
Lopes, I. L., Santos, F. A., \& Pinheiro, C. M. (2014). Inteligência Artificial. Rio de Janeiro: Elsevier. Moustris, G. P., \& Tzafestas, S. G. (2011). Switching fuzzy tracking control for mobile robots under curvature constraints. Control Engineering Practice, 19(1), 45-53.

Nascimento Junior, C. L. (2004). Inteligência Artificial em Controle e Automação. São Paulo: Blucher.

Niku, S. B. (2014). Introductions to Robotics: Analysis, control, applications. New Jersey: Prentice Hall.

Pandey, A., \& Parhi, D. R. (2014). MATLAB Simulation for Mobile Robot Navigation with Hurdles in Cluttered Environment Using Minimum Rule Based Fuzzy Logic Controller. Procedia Technology, 14, 28-34.

Pereira, J., Galdino, A., \& Almeida, L. (2009). Robô para inspeção de áreas classificadas e de difícil acesso com transmissão de imagens sem fio. Holos, 4, 75-80.

Pradhan, S. K., Parhi, D. R., \& Panda, A. K. (2009). Fuzzy logic techniques for navigation of several mobile robots. Applied soft computing, 9(1), 209-304.

Resende, C. (Outubro de 2013). A nonlinear trajectory tracking controller for mobile robots with velocity limitation via fuzzy gains. Control Engineering Practice, 21(10), 1302-1309.

Romero, R. A., Preste, E., Osório, F., \& Wolf, D. (2014). Robótica Móvel. São Paulo: LTC.

Siegwart, R. (2004). Introduction to Autonomous Mobile Robots. Massachusetts: Massachusetts Institute of Technology.

Silva, J. L. (2012). Uma plataforma multipropósitos para ensino de automação e redes industriais. Anais do XIX Congresso Brasileiro de Automátic, 2088-2094.

Simões, M. G. (2007). Controle e Modelagem Fuzzy. São Paulo: Blucher.

Zaki, A. M. (2014). Microcontroller-based mobile robot positioning and obstacle avoidance. Journal of Electrical Systems and Information Technology, 1(1), 58-71. 